\title{
Research on the Schemes of Carrying Multi Service LTE Power Wireless Network

\author{
Qing Liu
}

State Gird Jiangxi Electric Power Research Institute

Keywords: LTE; Wireless Network; Distribution Automation; Electric Power System

\begin{abstract}
Distribution network is smart grid connected power grid and important components for power users, is the key link of the normal operation of the whole power system. With the rapid development of China's national economy, the country has begun to carry out the construction and transformation of urban and rural power grid, for the intelligent distribution network and information technology has become the focus of this series of transformation. Distribution network information monitoring, analysis, processing, decision-making need information transmission can be realized through a reliable and efficient communication platform, and thus enhance the reaction time of system failure and maximum reduces the loss caused by faults in the distribution network. Therefore, there is an urgent need construction technology of advanced, meet the requirements of the distribution network intelligent access layer communication platform.
\end{abstract}

\section{Introduction}

With the increasing diversification of demand for the smart grid of communication, to LTE technology as the representative of the new wireless network communication technology application in electric power communication system is more and more attention. Zhejiang, Guangdong and other power companies in recent years have carried out such as TD-LTE230 $\mathrm{MHz} / 1.8 \mathrm{GHz}$ distribution and utilization electric pilot wireless communication network construction and exploration of application based on various technical systems. A new wireless communication technology in transmission rate, reliability, real-time and maintenance difficulty degree with wired communication incomparable advantage, can naturally adapt to the communication terminal number, short distance communication, node communication data amount is small, is affected by the distribution network expansion and urban construction equipped with electric communication access network.

The existing electric power communication network of each business area is independent of the generation and development of communication network, so the corresponding has been separate construction according to business needs. Independent mode of the network cannot make full use of communication resources. Unified operation and maintenance management is not conducive to the equipment. In this paper, combining the LTE wireless communication network architecture, based on the loading condition of the power communication business analysis, put forward a LTE system design and isolation scheme

\section{Demand of Distribution Network Communication Service}

With the development of GIS application system, outage management system, fault repair service system, distribution work management system automation and intelligent, distribution master station, substation and distribution terminal between the size of the data transmission will be more and more big, the performance of data transmission request is getting higher and higher. Therefore, a new type of broadband access communication technology is needed to support the communication technology in the process of intelligent distribution network. According to the characteristics of various kinds of information sensing, monitoring, intelligent control and other services in smart distribution network, the intelligent distribution network access layer communication system needs to meet the following requirements. 
1) Save the cost, improve the efficiency, reduce the operation complexity. Distribution network system has many characteristics, such as complex structure, complex operational environment, and equipment and so on. If the distribution network communication network with complex structure will cause the management cost of upgrading, and once the fault of the distribution network and communication platform will be able to achieve rapid and effective fault location.

2) Meet the needs of a variety of business isolation services in the intelligent transformation. Traditional narrowband communication systems have been unable to meet this demand. Therefore, in view of the future smart distribution network in different business needs, need to focus on the current, long-term planning, by quickly and effectively absorb advanced technology achievements in the field of mobile communication is developing distribution network access layer communication network construction to speed up the distribution network intelligent process to promote, enhance the vitality of the smart grid.

3) Meet the demand of high reliability and low transmission delays in the process of data transmission. Different from the traditional communication network, intelligent power distribution network communication system put forward higher requirements for the reliability of data transmission. Distribution network access layer communication system must be safe and reliable network, the need to provide delay controllable high reliability data transmission services for all types of business, according to the characteristics of the distribution business, the distribution network communication system requirements of data transmission end to end delay is less than 15 ms. However, traditional technology cannot meet the communication requirement of delay, need to find new communication technologies to meet the requirements.

\section{Communication Technology of Distribution Network Automation}

The network structure and the regional characteristics of the distribution system determine the communication network structure is complex, decentralized distribution, multi node, poor working environment and so on characteristics, making communication technology selection is very complex. The current distribution network communication system technology scheme is used in an optical fiber communication, medium voltage power line carrier communication, wireless public network communication, wireless network communications and so on.

The structure of distribution network automation system is generally divided into three layers, namely the main station system layer, the communication system layer and the terminal system layer. Usually set up a station automation system in the Council's dispatch center, through the electric power communication network or wireless network will collect the data to the terminal unified distribution automation system centralized processing station. The typical structure of distribution network automation system is shown in Fig. 1: 


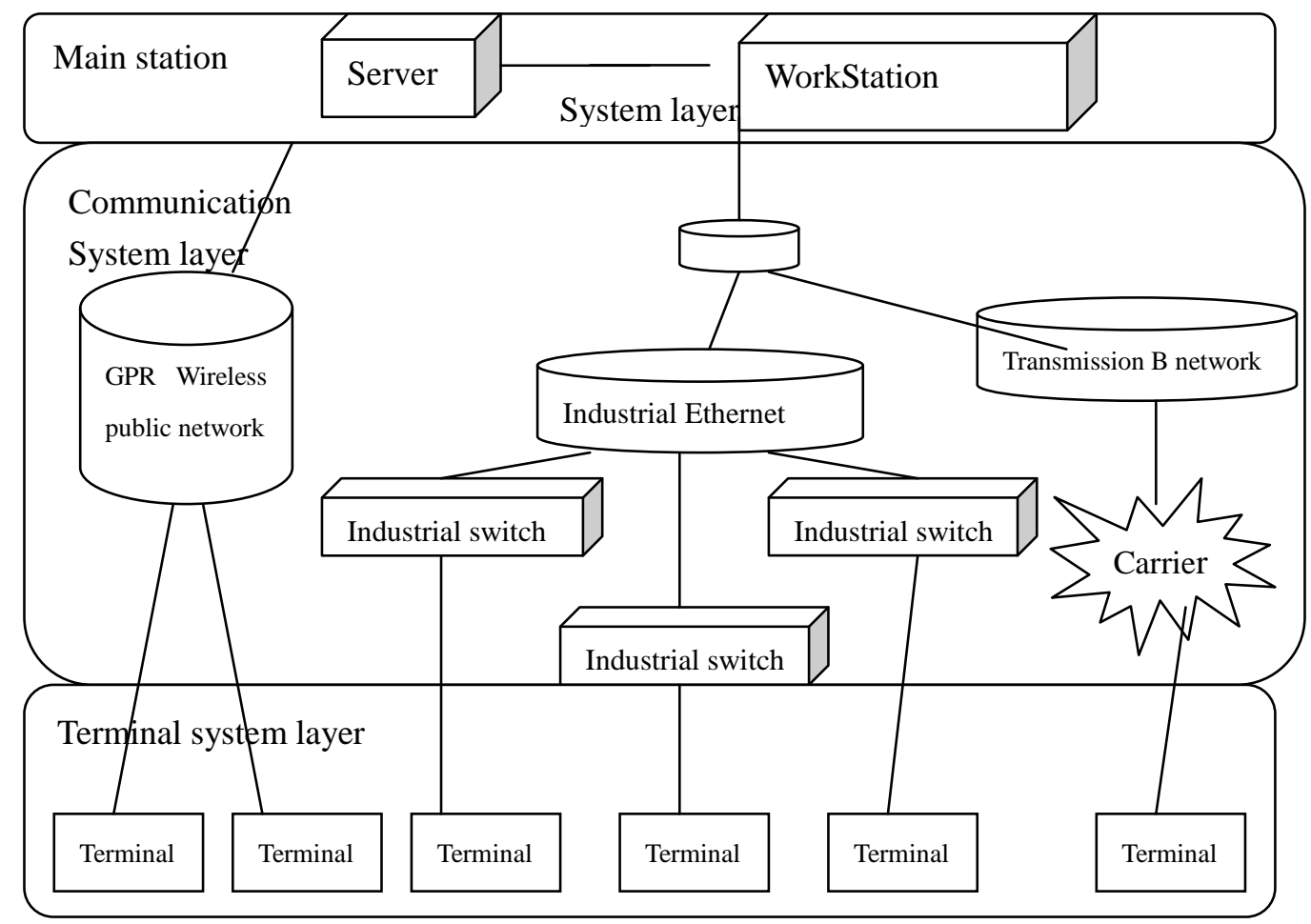

Figure 1. Structure Diagram of Distribution Network Automation System

Similar to the distribution automation system, network communication system is generally divided into three layers, including the backbone network, access network and communication terminal layer. The access layer to preprocess information, according to the importance of screening and then upload, to avoid congestion of information. The backbone communication network is to realize the communication of distribution network communication substation to the main station of distribution network communication; Access to a communication network is the main communication terminal layer to network communication substation, communication technology can be used commonly include optical fiber communication, wireless communication technology, communication carrier.

\section{Electric Power LTE System Deployment Architecture}

LTE system is composed of Evolved Universal Terrestrial Radio Access Network, E-UTRAN and Evolved Packet Core, EPC. Evolved Node B is the only functional entity that is composed of E-UTRAN, including BBU and Radio Remote Unit 2 parts. BBU and RRU through the Public Radio Interface standard optical fiber connection. EPC is composed of MME and S-GW. The main function of MME is mobility control, and S-GW is the main function of the data packet routing forward. In practical application is usually integrated in core network equipment. ENB through the $\mathrm{X} 2$ interface between the connection, LTE access network and core network through the S1 interface connection. Compared to the $3 \mathrm{G}$ network, the LTE system uses flatter network architecture. The network architecture of LTE system is shown in Fig. 2. 


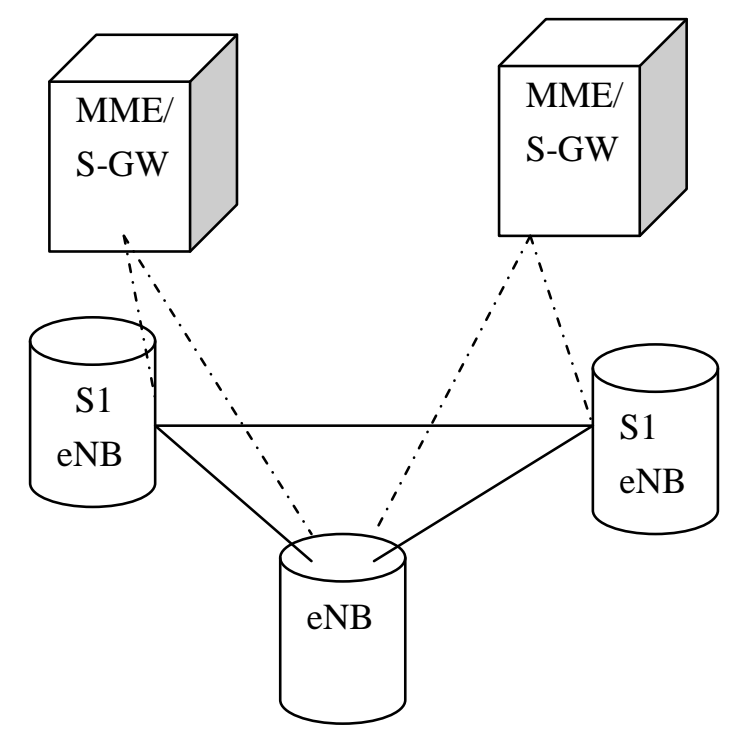

Figure 2. LTE System Network Architecture

\section{Conclusion}

Based on network communication to meet the same business needs, power wireless network has the obvious advantage of the cost of investment. The investment cost is mainly composed of base station construction cost and wireless terminal purchase cost, the communication cost of each distribution network is related to the scale of business, the larger the scale, the lower the cost of the single point. At the same time, the construction of power wireless network will greatly promote the development of smart distribution grid while driving demand in the information and communication industry, with significant economic benefits. Powerful wireless network can provide a large number of equipped with electrical terminals provide a flexible, reliable and low cost communication access way and also to the security and confidentiality of data services to provide better security. In this paper, the development trend of power system communication network is the unification of the service load and network construction. LTE system as a new solution for terminal communication access network, can achieve the basic requirements of multi service bearer. In the realization method, the LTE network structure and the current situation of the electric power backbone communication network should be integrated, and the design of the multi service bearer architecture can meet the requirements of the service load and data security.

\section{References}

[1] Shea J J. Electric power system applications of optimization [Book Reviews] [J]. IEEE Electrical Insulation Magazine, 2001, 17(6) :62-62.

[2] Voropai N I, Ivanova E Y. Multi-criteria decision analysis techniques in electric power system expansion planning[J]. International Journal of Electrical Power \& Energy Systems, 2002, 24(1) :71-78.

[3] Zhan Y, Cheng H. A robust support vector algorithm for harmonic and intergalactic analysis of electric power system[J]. Electric Power Systems Research, 2005, 73(3) :393-400.

[4] Kataoka Y. A probabilistic nodal loading model and worst case solutions for electric power system voltage stability assessment[J]. IEEE Transactions on Power Systems, 2003, 18(4) :1507-1514.

[5] Lopes J A P,. F J, Almeida P M R. Integration of Electric Vehicles in the Electric Power System[J]. Proceedings of the IEEE, 2011, 99(1):168-183. 
[6] Chen Z, Luo Y, Chen M. Control and Performance of a Cascaded Shunt Active Power Filter for Aircraft Electric Power System[J]. IEEE Transactions on Industrial Electronics, 2012, 59(9) :3614-3623.

[7] Malagueta D, Szklo A, Borba B S M C, et al. Assessing incentive policies for integrating centralized solar power generation in the Brazilian electric power system[J]. Energy Policy, 2013, 59(1):198-212.

[8] Zhang F, Geng Z, Yuan W. The algorithm of interpolating windowed FFT for harmonic analysis of electric power system[J]. Power Delivery IEEE Transactions on, 2001, 16(2) :160-164.

[9] Anagnostopoulos J S, Papantonis D E. Study of pumped storage schemes to support high RES penetration in the electric power system of Greece[J]. Energy, 2012, 45(1):416-423.

[10]Bhuiyan R H, Dougal R A, Ali M. A Miniature Energy Harvesting Device for Wireless Sensors in Electric Power System[J]. IEEE Sensors Journal, 2010, 10(7) :1249-1258.

[11]Billinton R. Evaluation of reliability worth in an electric power system[J]. Reliability Engineering \& System Safety, 1994, 46(1) :15-23.

[12] Overbye T J, Weber J D. New methods for the visualization of electric power system information[J]. Information Visualization. Informs.ieee Symposium on, 2000:131-16c. 